\title{
Virtually Authentic: Graduate Students' Perspective Changes toward Authentic Learning while Collaborating in a Virtual World
}

\author{
Songhee Han and Paul E. Resta \\ Department of Curriculum and Instruction, The University of Texas at Austin
}

\begin{abstract}
This qualitative case study investigates graduate students' perspective changes apropos their crossnational collaborative learning experience while participating in an online teaching and learning course jointly taught by graduate schools in the United States and Israel. The participants met virtually, on a weekly basis between November and December 2018, on a platform called Second Life, to design and participate in collaborative learning activities. On completion of the course, interviews were conducted with a small sample of student-participants regarding their experiences. During the design phase, participants' dominant perceptions of their learning experiences were characterized by genuine "excitement" at the novelty of collaborating virtually with colleagues on the other side of the world. Their initial perceptions evolved during the participation phase to realization as learning communities emerged and students' roles expanded beyond the scope of mere participants. In this study, the authors argue that participants' construction of new knowledge resulted in authentic learning from the standpoints of social constructivism and online collaborative learning theory and further discuss the factors that enabled the participants' authentic learning experience.
\end{abstract}

Keywords: virtual reality, collaborative learning, authentic learning, computer-supported collaborative learning, three-dimensional learning environment

Han, S., \& Resta, P.E. (2020). Virtually authentic: Graduate students' perspective changes toward authentic learning while collaborating in a virtual world. Online Learning, 24(4), 527. https://doi.org/10.24059/olj.v24i4.2326

\section{Virtually Authentic: Graduate Students' Perspective Changes toward Authentic Learning while Collaborating in a Virtual World}

Over the past decade, a significant amount of effort has been made to integrate emerging technologies in online education. When it comes to higher education, the integration trend is seemingly becoming more focused on providing transformative yet authentic learning experiences using immersive technologies such as virtual worlds in lieu of simple web-based tools like wikis, 
blogs, or Google applications. Furthermore, we can foresee the increased adoption of immersive technologies including virtual world in the near future given their cost-effectiveness in providing immersive learning platforms (Monahan et al., 2009; Ramírez et al., 2018; Reinsmith-Jones et al., 2015). The current pandemic situation has also engendered increased demand for off-campus learning experiences, offering connectivity with classmates from the safe confines of home (Bronack et al., 2008).

According to existing literature (De Lucia et al., 2009; Murray, 2015), the most commonly used virtual world in higher education thus far is Second Life (SL). Early in the twenty-first century, educational researchers began studying SL as a learning environment from multiple aspects such as: (a) creating online identities that differentiate from offline identities (Baker et al., 2009; Burbules, 2002; Gee, 2004; Turkle, 1995); (b) using avatar interactions to overcome real-world barriers (Dickey, 2005; Gee, 2004; Lee, 2009); (c) providing simulated representations (Broadribb \& Carter, 2009; Stott, 2007); (d) creating a better community of practice (Boulos et al., 2007; Wenger, 1998); and more recently, focusing considerable attention on (e) enhancing social presence and creating learning communities (Bronack et al., 2006; De Lucia et al., 2009; Resta and Shonfeld, 2014; Warburton, 2009).

Several recent virtual world studies in the field of education have reported on the ways in which teaching and learning in a virtual world facilitates collaborative learning and promotes the emergence of learning communities in classrooms from the social constructivist standpoint. These studies have revealed role reversals in these learning communities, allowing students to take on the roles of teachers or experts while teachers become learners with their students and broaden their perspectives on learning and teaching (Boniello et al., 2019; Bronack et al., 2008; Chanprasitchai, 2016; Kostarikas, 2016). Some of these studies have also indicated that learning communities created by the adoption of virtual world enforce students' reflective learning processes and encourage students' learning motivation and engagement (Boulos, 2007). Nonetheless, a detailed examination of students' perception changes, concerning their learning experiences through such collaborative processes in a virtual world, has not been undertaken thus far. In addition, examining collaborative learning activities in a virtual world, in relation to the knowledge construction process, would be useful in analyzing interactions between participants to evaluate learning authenticity, but this aspect seems to be insufficiently understood in the education sector due largely to the scarcity of preexisting studies.

The primary purpose of this study is to examine the changes, per course phase, in students' perceptions of their own learning experience and, thus, evaluate the authenticity of learning during their participation in a cross-national collaborative course on the SL platform. The secondary purpose is to gain a detailed understanding of the students' knowledge construction process throughout the course in conjunction with the produced knowledge per course phase and learning authenticity. Thus, this study is guided by the following research questions:

(1) What were students' perceptions regarding their collaborative learning experience while designing team-based learning activities in a virtual world?

(2) What were students' perceptions regarding collaboration while participating in team-based learning activities designed by other teams in the virtual world?

(3) What, if any, were the changes in students' perceptions regarding collaboration between the design and participation phases of learning? 
(4) What knowledge did students construct per course phase and what overarching themes were identified during the knowledge construction process from the standpoint of the online learning community theory?

\section{Review of Related Literature}

\section{Authentic Learning in Virtual Worlds}

Authentic learning has been conceptualized in various ways in educational literature. Predominantly, these different concepts emphasize learning activities in the real-world context, however, some of these concepts can be applied to a virtual context. For example, Brown et al. (1989) described authentic learning as "the ordinary practices of the culture" (p. 34) and focused more on providing a safe learning environment for students in the real-world. When safety is guaranteed, students can become independent participants in the community within that culture. Lave and Wenger (1991) also mainly focused on the physical presence of students in a community. They argued that legitimate and peripheral participation enables authentic learning within the community to which the students belong. In such cases, students lean heavily on the guidance and mentoring of experienced members and they are not expected to become independent participants in the community. Neither Brown et al. (1989) nor Lave and Wenger (1991) applied their ideas to a virtual context. Viewed strictly, it is presumed that a virtual world cannot be conceived as an authentic learning environment in both approaches because students are not in the physical community where they live and breathe.

Unlike Brown et al. (1989) and Lave and Wenger (1991) who focused more on the physical prerequisites of an authentic learning environment, Heath and Mclaughlin (1994) and Hierbert et al. (1996) had a more student-centered approach that considered students' individual differences and different contexts of learning rather than focusing on the physical environment where learning occurs. They argued that authenticity in learning could be achieved by offering learning activities that align with a student's personal perception and contextual elements of the real world. From this perspective, authentic learning consists of experiences, which students can meaningfully connect to within the context of their own lives, and measurable changes comparing the before and after the learning experience. Notably, there is no absolute requirement for a physical environment. To this end, a virtual world can be viewed as a possible authentic learning environment as long as it meets student-centered criteria including providing opportunities for personal expression via manipulation of one's own virtual space and identity such as avatar customization.

Based on a similar student-centered approach, but with a focus on the fluid aspects of culture construction, Van Oers and Wardekker (1999) defined authentic learning as stated below:

Authentic learning is the dynamic relation between a personality-under-construction and cultural practices-being-reconstructed, which is aimed at developing an authentic and autonomous person able to participate in a competent, yet critical way in cultural practices. (p. 231)

For this case study, we adopted the definition of 'authentic learning' from Heath and Mclaughlin (1994) and Hierbert et al. (1996) primarily because their approaches allow the possibility of virtual worlds as places of authentic learning and help explain how SL's social features enhance collaborative interactions between participants, leading to authentic learning for students. In 
addition, we adopted Van Oers and Wardekker (1999)'s approach to analyze the learning process regarding cultural renewal and refreshment inside and outside the team-based activities. This approach additionally benefitted the authors in recognizing the emergence and evolution of learning communities over time.

\section{Collaborative Learning in Virtual Worlds}

One of the most attractive aspects of using virtual worlds for collaborative learning is the enhanced peer teaching and learning that takes place. Especially when it comes to team-based projects, learning is usually driven by interactions with peers while exploring virtual worlds together. Rapid interpretation exchanges between students can lead to an extensive understanding of others' perspectives while also helping students to decide what the most reasonable interpretation is in a given situation (Greenwald et al., 2017). Likewise, many researchers have argued in previous studies that social interaction in a virtual world is the most influential factor contributing to student's learning authenticity. They further posit that the process of this interaction is more important than the outcome of learning itself (Dillenbourg, 1999; Mercer \& Howe, 2012; Scardamalia \& Bereiter, 2006; Vuopala et al., 2015).

When it comes to cross-national team-based collaborative learning, the process of interaction between students increases in complexity given the issue of intercultural literacy. Heyward (2002) explained the functionality of intercultural literacy as enabling one to "interpret its symbols and negotiate its meanings in a practical day-to-day context" (p. 10). In the absence of intercultural literacy, interactions can lead to "misunderstandings and intercultural blunders that can be extremely costly to both individuals and organizations" (p. 10). Intercultural learning thus, occurs when interactions in cross-cultural situations take place over significant amounts of time during which members exert equal participation.

In this case study, our definition of the term, 'collaborative learning,' focuses on the interand intra-team interactions between students. Informed by the approach adopted by previous researchers, we paid keen attention to the students' learning process rather than focusing on their learning outcomes. It should be noted, however, that despite identifying the issue of intercultural literacy in our dataset, we could not find conclusive evidence of whether or not intercultural learning occurred due to the short period of students' interaction spanning just five to six weeks. As a result, we did not cover the intercultural learning component in this study.

\section{Conceptual Framing}

We used social constructivism and online collaborative learning theory in this study. Social constructivism (Vygotsky, 1978) was applied to investigate graduate students' perspective changes and the role peers played in their learning dynamics. In other words, social constructivism was the tool we employed to observe the process of participants' learning. To examine how knowledge was constructed in the different phases of learning, we adopted the online collaborative learning theory (Harasim, 2012) and analyzed the dominant themes that appeared in each phase to identify the components encompassing participants' authentic learning.

\section{Social Constructivism}

Lev Vygotsky (1978) argued that knowledge is co-constructed in social environments through social interactions. Since language use is crucial in determining whether social interactions are contributing to successful meaning-making, it was regarded by Vygotsky as the central tool in the learning process. However, he made a distinction between knowledge and learning. In keeping 
with other social constructivists, Vygotsky explained that while learning may occur through collaboration, it is still an internal mechanism that takes place within the individual. After learning transpires at the individual level through social interaction, the subsequent internalization of the knowledge can occur both at individual and social levels (John-Steiner \& Mahn, 1996). Vygotsky proposed the concept of "zone of proximal development (ZPD)" and argued learning involves moving from the ZPD to the "zone of actual development (ZAD)" through an active meaningmaking process constituting social interactions with others. In summary, learning, which is a process involving conversations and interactions with others, is crucial to knowledge generation, which is the final product of learning.

Considering a virtual world as a learning environment through a social constructivist lens, the use of SL in the current course to design learning activities created reasons for students to explore the world together, discuss, and implement the creation of activities in this space (Lave \& Wenger, 1991; Wenger, White, \& Smith, 2009). As individual participants brought their unique ideas to bear, in terms of how to use the space and how to design learning activities, the learning environment stimulated social interaction while enabling them to take ownership of the knowledge creation process. Furthermore, each student had abundant opportunities to see their ZPD evolve to the ZAD both through interactions within their own groups as well as with the class at large.

\section{Online Collaborative Learning (OCL)}

Online Collaborative Learning has its roots in social constructivism, as students are encouraged to solve problems and/or participate in projects collaboratively through active social interactions. Harasim (2012) describes OCL as:

A new theory of learning that focuses on collaborative learning, knowledge building, and Internet use as a means to reshape formal, non-formal, and informal education for the Knowledge Age. (p. 81)

In this study, the three phases of knowledge construction defined by the OCL theory-idea generation, idea organization, and intellectual convergence - were used to explore and analyze the students' perceptions apropos designing and participating in collaborative team-based learning activities. OCL describes the teacher's role as a facilitator as well as a learning community member who engenders peer discourse by facilitating interaction among participants. As this study was conducted within a course offered at the graduate level, the two course professors in both countries served as mediators between the small-sized teams as well as the whole class. They motivated the students to proceed on to the next phase of learning and balanced feedback per team. Therefore, OCL was useful in interpreting the overall interactions between students, a student and a group of students, and student(s) and teacher(s) in this study. However, we specifically focused on gathering students' perceptions (and deciphering the meaning of their perceptions) of each learning phase resulting from interactions with peers using the three phases of knowledge construction of OCL. Hence, the teachers' roles are not discussed in this study. 


\section{Methods}

\section{Research Design}

This qualitative case study examined how participants of the Computer-Supported Collaborative Learning course perceived their collaborative learning experience. The qualitative research method was adopted to interpret and understand the participants' perceptions of events that took place through the duration of the course (Denzin \& Lincoln, 2005). The case in this study was selected on its own merits (Stake, 1995), because many course participants expressed their thoughts on this unique learning experience upon course completion, which in turn elicited genuine interest from the authors. The goal of this intrinsic case study was to "investigate a contemporary phenomenon in depth and within its real-life context" (Yin, 2009, p. 18). To measure the participants' perspective changes between the design and participation phases, in-depth interviews were conducted, with each study participant, regarding their collaborative learning experience per course phase, using semi-structured interview questions (see the Appendix 1).

\section{Setting: Graduate-level Courses in the U.S. and Israel}

This graduate-level and fully-online course- "Computer-Supported Collaborative Learning/Online Environments for Teaching and Learning" (course titles in the U.S and Israel respectively) - was offered separately by learning technology programs in graduate schools located in both the U.S. and Israel in 2018. The course aimed to help students experience, engage in and understand the ways in which computer-supported collaborative learning may be used to enhance the teaching-learning process. Through this course, students learned to effectively use a range of contemporary tools, such as wikis, threaded discussion boards, and multi-user virtual environments, (SL in this case) to support online collaborative learning. For the most part, students in the U.S. and Israel primarily engaged in coursework with colocated classmates in English and Hebrew, respectively. For a five to six weeks period (from November through December 2018), however, participants of the course in both countries had the opportunity to collaborate. Crossnational teams were created, and each team collaborated in designing team-based learning activities in SL. Each team subsequently engaged with learning activities designed by other teams a week before the collaboration ended. The collaboration between the two countries during this period was conducted solely in English.

This partnership between these two graduate schools was established to understand the ways in which technology is overcoming the barriers of time and space in the context of learning and work. Thus, students in both classes were intentionally placed in virtual teams comprising peers of their own residency as well as students from a different country and time zone. This partnership between the two classes began more than five years ago and SL, with its many sophisticated features, including the Learning Island where the virtual auditorium resides, was selected as the main platform for the current collaboration as well. Moodle was selected as the learning management system for the course, which enabled students from both countries to form teams, use forums, and submit assignments.

Collaboration between the students from both countries comprised of two phases-design and participation. In the design phase, the teams developed educational, multi-stage, collaborative learning activities within SL. For example, a team designed a math learning activity consisting of three stages: (1) "visiting" a nearby playground in a specific zone in SL; (2) locating a pyramidshaped play structure; and (3) taking a screenshot while playing on the structure with team members. In the participation phase, a week before the course ended, each team participated in an 
SL-based event called "The Amazing Race" with the objective of completing as many of the learning activities designed by other teams as possible. During this 90 -minute event, each team had six learning activities to complete excluding the learning activity their own team developed.

\section{Data Sources and Collection Processes}

Twelve study participants were recruited from both classes (six from the U.S. \& six from Israel; total number of students enrolled in the U.S. $=7, \&$ total number of students enrolled in Israel $=15)$. Each team $(n=7)$ comprised three to four students with the ratio of students from the U.S. to peers in Israel being approximately 1:2.

Recruitment for this study was conducted after receiving approval from an institutional review board. The students were contacted by email and provided with information about the study. All study participants provided consent via direct responses to the initial email. Of the 12 study participants, 6 identified themselves as females while the remainder identified as males. The native languages of participants included Arabic $(n=4)$, English $(n=1)$, Hebrew $(n=1)$, Korean $(n=$ $2)$, Mandarin $(n=3)$, and Russian ( $n=1$; see Table 1 for the detailed demographics of study participants).

Twelve interviews were completed online by August 5th, 2019 using Zoom and Skype (see Appendix 1 for interview questions). The first author conducted all six interviews of the students based in the U.S. in English; a multilingual collaborator conducted the remaining six interviews of the Israel-based students in Arabic or Hebrew and subsequently translated their responses into English.

Table 1

Participants' Key Information: Age, Country of Residence, Mother Tongue, English Proficiency, and Background Knowledge of SL

\begin{tabular}{llllll} 
Name & Age & & Mother tongue & English proficiency & $\begin{array}{l}\text { Background } \\
\text { experience in SL }\end{array}$ \\
\hline Mary & $25-34$ & U.S. & Mandarin & Advanced & $\begin{array}{l}\text { Heard of it, but no } \\
\text { experience }\end{array}$ \\
Mitch & $25-34$ & U.S. & Mandarin & Advanced & None \\
Elsa & $25-34$ & U.S. & English & Expert & None \\
Michael & $25-34$ & U.S. & Mandarin & Advanced & None \\
Kory & $35-44$ & U.S. & Korean & Advanced & None \\
Kelly & $35-44$ & U.S. & Korean & Advanced & None \\
Ali & $35-44$ & Israel & Arabic & Advanced & None \\
Adele & $45-54$ & Israel & Arabic & Below intermediate & $\begin{array}{l}\text { Heard of it, but no } \\
\text { experience }\end{array}$ \\
Allen & $25-34$ & Israel & Arabic & Intermediate & None \\
Amy & $25-34$ & Israel & Arabic & Intermediate & $\begin{array}{l}\text { Heard of it, but no } \\
\text { experience }\end{array}$ \\
Robert & $45-54$ & Israel & Russian & Advanced & $\begin{array}{l}\text { Heard of it, but no } \\
\text { experience }\end{array}$ \\
Harry & $25-34$ & Israel & Hebrew & Below intermediate & None
\end{tabular}


Table 2

Themes and Coding Examples of the Interviews

\begin{tabular}{|c|c|c|c|}
\hline Phase & $\begin{array}{l}\text { Overarching } \\
\text { Theme }\end{array}$ & Sub-Theme & Sample of Coded Text \\
\hline \multirow[t]{7}{*}{ Design } & \multirow[t]{3}{*}{ Novelty } & Excitement & $\begin{array}{l}\text { It felt awesome to talk and work with people so far away } \\
\text { from where I was in SL... }\end{array}$ \\
\hline & & Curiosity & $\begin{array}{l}\text { It was really cool to see myself (avatar) flying here and } \\
\text { there like a bird and see like a bird from top to bottom... }\end{array}$ \\
\hline & & Surprise & $\begin{array}{l}\text { It was totally surprising to see how many sophisticated } \\
\text { mini-worlds were out there in SL... }\end{array}$ \\
\hline & \multirow[t]{3}{*}{$\begin{array}{l}\text { Challenges and } \\
\text { Strategies }\end{array}$} & $\begin{array}{l}\text { Language } \\
\text { barrier }\end{array}$ & $\begin{array}{l}\text {...I understand English, but my English is not as good as } \\
\text { Arabic. So it was hard this time... }\end{array}$ \\
\hline & & $\begin{array}{l}\text { Steep } \\
\text { learning } \\
\text { curve of SL }\end{array}$ & $\begin{array}{l}\text { While I was lost in the middle of the learning island (where } \\
\text { a virtual auditorium was located), my professor tried to } \\
\text { help [guide] me [with directions] for more than } 30 \text { minutes } \\
\text { [during] class and I felt really sorry... }\end{array}$ \\
\hline & & $\begin{array}{l}\text { Moodle } \\
\text { interface }\end{array}$ & $\begin{array}{l}\text {...learning how to use Moodle was another learning task } \\
\text { for me in addition to how to use SL... }\end{array}$ \\
\hline & $\begin{array}{l}\text { Learning } \\
\text { Communities }\end{array}$ & $\begin{array}{l}\text { Social } \\
\text { presence }\end{array}$ & $\begin{array}{l}\text { It was comforting to realize that everyone was struggling } \\
\text { while we shared our difficulties in using } S L . . .\end{array}$ \\
\hline \multirow[t]{8}{*}{ Participation } & \multirow[t]{4}{*}{ Novelty } & Excitement & ...I could feel my heart was racing fast out of excitement... \\
\hline & & Engagement & ... Please give us more time! \\
\hline & & Curiosity & $\begin{array}{l}\text {...I was curious about what other teams had been working } \\
\text { on for the whole semester... }\end{array}$ \\
\hline & & Confidence & $\begin{array}{l}\text {...I felt confident in doing this kind of project with } \\
\text { international collaborators in the future... }\end{array}$ \\
\hline & $\begin{array}{l}\text { Challenges and } \\
\text { strategies }\end{array}$ & Limited time & $\begin{array}{l}\text { We really needed more time to explore the mini-worlds and } \\
\text { find clues... }\end{array}$ \\
\hline & \multirow[t]{3}{*}{$\begin{array}{l}\text { Learning } \\
\text { communities }\end{array}$} & $\begin{array}{l}\text { Class-based } \\
\text { learning } \\
\text { community }\end{array}$ & $\begin{array}{l}\text { We (her team) were surprised to see how they (another } \\
\text { team) used the mini world well, such as a Chinese } \\
\text { traditional building... }\end{array}$ \\
\hline & & $\begin{array}{l}\text { Constructive } \\
\text { critiques }\end{array}$ & $\begin{array}{l}\text { It would have been much better if they had presented the } \\
\text { instructions with more detailed steps and screenshots... }\end{array}$ \\
\hline & & $\begin{array}{l}\text { Employment } \\
\text { of multiple } \\
\text { competences }\end{array}$ & $\begin{array}{l}\text { It was challenging to coordinate all of the operations...I } \\
\text { wasn't sure what we should do or sometimes we didn't } \\
\text { reach the same place... }\end{array}$ \\
\hline
\end{tabular}




\section{Data Analysis}

All identifiers related to each participant were removed from transcriptions following which textual transcriptions were imported into NVivo. Coding was completed using constant comparison (Strauss and Corbin, 1990), whereby the text was first open-coded to identify emergent codes related to the phases of learning (either design or participation) and the graduate students' perspective changes. Open-coding generated 40 codes related to the design phase and 44 codes related to the participation phase. These codes were then refined and categorized using axial coding, which identified relationships among the open codes per phase. Finally, selective-coding led to the identification of overarching themes related to the design $(n=3)$ and participation $(n=3)$ phases, with different distributions of dominant overarching themes per phase (see Table 2 for coding examples of interviews).

\section{Validity}

All interview responses were recorded. Next, participants' names were changed to pseudonyms with the first letter representing their mother tongue to protect their identities. Then, the recordings were transcribed, and participants' responses were coded using NVivo. The first author subsequently analyzed the data by creating a list of related open codes. The second author reviewed codes to ensure interrater reliability. Any discrepancies were discussed until a consensus was reached between the authors.

The Israeli participants confessed to experiencing language barriers on more than one occasion. Thus, to accurately gather their perceptions regarding collaboration, a multilingual liaison was invited to conduct the interviews of Israeli students either in Arabic or Hebrew. The accuracy of participants' responses translated into English was double-checked by the authors and any vague or unclear translations were discussed until a consensus was reached between the authors and the multilingual liaison.

\section{Results}

Using the first two research questions as a guide, the coded data were categorized into the design and participation phases. Each theme that emerged was directly related to research questions 1 and 2, and the findings were inferred through a social constructivist lens. Data based on participants' interview responses revealed three major categories in the students' perceptions regarding designing team-based learning activities: novelty, challenges and strategies, and learning community.

\section{Research Question 1 (RQ1): What were students' perceptions regarding their collaborative learning experience while designing team-based learning activities in a virtual world?}

\section{Novelty}

Of the 40 open codes generated in the design phase, 27 were related to feelings of novelty. Some students expressed (a) their excitement, curiosity, and surprise with respect to the realistic three-dimensional representations found within SL. They shared that these feelings prompted multiple explorations of the mini-worlds inside SL. For example, Ali said, "It was a good experience, and I felt that I'm not only playing now, I'm also building it. I liked that." Leslie said, "It was totally surprising to see how many sophisticated mini-worlds were out there in SL, and [I] found myself enjoying wandering around a lot." Other participants, Amy and Robert, elaborated 
on their amazement in (b) collaborating with peers residing far away in a language other than their own mother tongues. Finally, others expressed their novel feelings in (c) using SL avatars and traversal systems. A participant named Kory said "It was really cool to see myself (avatar) flying here and there like a bird and see like a bird from top to bottom. I loved the teleporting feature too in SL and [so much] so that I sometimes lost track of time in exploring the world using all these features."

\section{Challenges and Strategies}

Eighteen out of 40 codes were related to challenges and strategies regarding designing learning activities effectively with team members. The most significant challenge for participants included: (a) the language barrier, (b) the steep learning curve of SL's user interface, and (c) the challenge of navigating a new learning management system (Moodle). Although only one of the 12 participants was a native English speaker (see Table 1), English was used as the medium of communication throughout the collaborative period. This language barrier negatively impacted the collaborative experience for some. For example, Adele said "As I experienced in other courses, it was very easy to work with my team members when I used Arabic in SL. I understand English, but my English is not as good as Arabic. So, it was hard this time." To overcome the language barrier, many teams, according to Mitch, Kelly, and Allen, decided to use supplementary webbased communication tools such as WhatsApp and WeChat, to preserve records of their conversations for future reference as understanding each other in real-time was difficult. Students additionally reported the challenge of familiarizing themselves with SL. Elsa stated, "I needed a lot of help from my professor and classmates to be comfortable with all [of the] features in SL, especially at the beginning. While I was lost in the middle of the learning island (the location of a class virtual auditorium), my professor tried to help [guide] me [with directions] for more than 30 minutes [during] class, and I felt really sorry for him and other classmates. I felt really bad." To ease the learning curve, Elsa mentioned tapping "good classmates" actively before and after the class sessions in addition to addressing questions to her professor, an expert in the use of SL for educational purposes. On the other hand, Kelly said she searched for tips online to get familiar with the SL user interface swiftly instead of waiting for help from classmates or the professor. She said, "I could catch up with others even though I had to miss a few class sessions out of family emergencies in this way." Lastly, in terms of using an unfamiliar learning management system, Leslie highlighted that Moodle was not as clear as Canvas, which she was already familiar with from previous courses. Hence, basic tasks such as submitting design documents and forum participation were difficult. She said "learning how to use Moodle was another learning task for me in addition to how to use SL."

\section{Learning Community}

Five out of 40 codes were related to the emergence of learning communities within teams. Since none of the participants had experience with SL prior to the course, many shared their frustrations with each other. Michael said, "I [told] myself that I am not the dumb one after all. It was comforting to realize that everyone was struggling while we shared our difficulties in using SL." Mary also mentioned that "Kelly was an excellent teacher for me. At first, I felt I would never get the hang of this, but she encouraged me that I can do this because she can do it and she's not a techie person at all. She pointed out some cool things we can do such as being teleported by a friend in SL and I finally got to the point that I can impart my knowledge of how to use SL interface to my Israeli team member later. Personally, it was a great success." 
RQ2: What were students' perceptions regarding collaboration while participating in teambased learning activities designed by other teams in the virtual world?

\section{Novelty}

During the participation phase, only 5 out of 44 open codes were related to feelings of novelty. The predominant sentiments that emerged in this phase were excitement, engagement, curiosity, and confidence based on competition related achievements. Harry experienced an "intensive immersion" from the very start when the two professors commenced the competition. He said, "When I saw my avatar standing in the auditorium (see Figure 1) with 20+ classmates and listened to what the professors explained about how to proceed in the Amazing Race, I could feel my heart was racing fast out of excitement. I was curious about what other teams had been working on for the whole semester, and I wished my team could win this race badly." Reflecting on post-participation, Amy stated, "I was very proud of what we all have accomplished during this course. We designed high-quality learning activities that fully took advantage of what SL could offer, and we confirmed those were fun and helped learners to achieve educational goals." Other participants confessed they felt very disappointed and frustrated when the professor announced the time was up, and all participants were told to return to the auditorium. These feelings are indicative of a strong sense of engagement with the Race. Ali said, "I felt like, are you kidding? I can do this for the whole day! Please give us more time!" Adele described her enhanced confidence in collaboration with cross-national team members as follows: "I'm not a good English speaker, but I managed to collaborate with my U.S. team members for this course and I felt confident in doing this kind of project with international collaborators in the future after the Amazing Race. It was a great finale [for] the class."

Figure 1. Virtual Auditorium in the Learning Island.

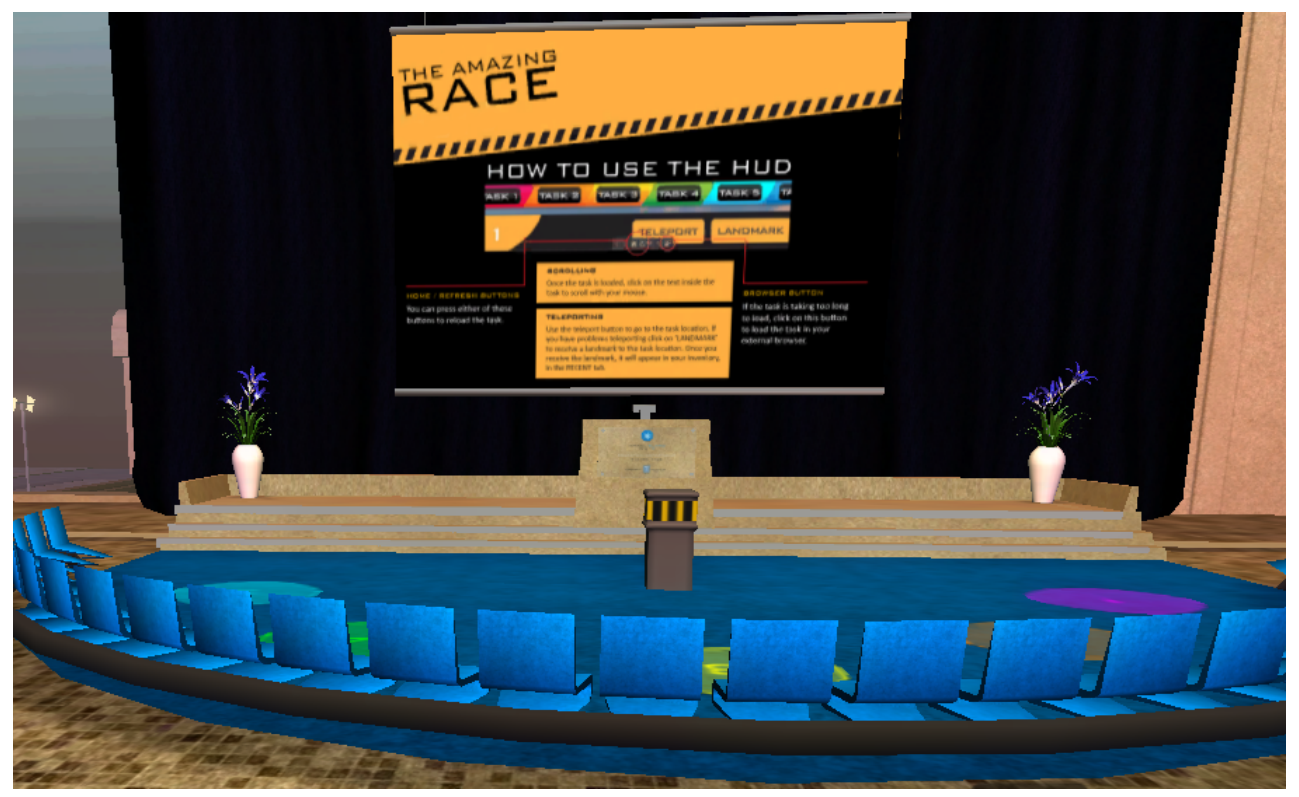

Note. A screenshot of the auditorium in SL on the Amazing Race day.

\section{Challenges and Strategies}

Eight out of 44 open codes were related to the various challenges and strategies that resulted from the competitive nature of the "Race" and the time constraint placed on it. Specifically, 
individual students employed strategies such as attempting the learning activities separately ahead of the competition to ensure increased contributions to the team during the Race itself as Kelly did ("I knew I would be much faster if I explore alone first and transport my team to where I was when I found a clue. I proposed this way to my team members before the Amazing Race began and I think it worked for us. We ended up being one of the winning teams"). In contrast, some participants chose to revisit the learning activities after the completion of the official competition to learn at their own pace as Elsa did ("I revisited the Amazing Race more than a couple of times by myself after the course ended. I wanted to solve the other problems I could not during the Race [because I ran] out of time. And, it was worthwhile because I had a real chance to see the full intentions of activities designed during the whole course much in detail this way"). With respect to strategies, different tactics were employed at the team level such as sequencing the activities from the easiest to the hardest (Leslie), sticking together as a group to complete learning goals as a team (Adele), splitting team members into pairs to tackle multiple activities simultaneously (Mitch \& Robert), and making smart use of SL's teleportation feature to win the competition (Leslie, Michael, Adele, \&Amy).

\section{Learning Community}

Thirty-one out of 44 open codes were related to the rise of a learning community among the students. In detail, (a) students from the small teams merged into the larger class-based learning community. Kelly and her team, for example, were inspired by how well other teams took advantage of SL's pre-built mini-worlds to provide contextualized learning experiences for other participants including Kelly and her teammates. She declared, "We (her team) were surprised to see how they used the mini world well, such as a Chinese traditional building, to teach and learn Chinese history. We all thought it was awesome." (b) Constructive feedback between the teams also emerged. Amy noted, "Some of the teams gave unclear instructions on their learning activities. It would have been much better if they had presented the instructions with more detailed steps and screenshots of specific places we needed to visit." Each team evaluated every other team's designs and many realized they were in an unstructured learning environment with complex problems to solve in a limited time. Kory called that environment "chaos" while Harry described it as "intense." To accomplish learning goals in this environment, teams were encouraged to (c) employ multiple competencies at the same time including communication, negotiation, and problem-solving. Michael described his learning experience post-participation as a "different kind of learning (that) happened." Ali elaborated on her experience as follows: "We set off, there was a competitive environment, which is funny that in my age I wanted to win at all cost. I must be ageless. I didn't know I'm that competitive and it turned out that I was...It was challenging to coordinate all of the operations with the cell phone next to my computer since many times we didn't hear each other and many times we didn't understand the instructions, or I wasn't sure what we should do or sometimes we didn't reach the same place, and we had to teleport each other and so many things happened at the same time!... We really had a passion to win and we did everything we could. No kidding. We were so serious, and we made it after all." Harry recalled what he said in the debrief session after the Amazing Race regarding (d) the unique class culture that emerged when the participation phase was over: "Anyone in the class would have experienced how passionate we were to win the Amazing Race as a team. Others outside this course would never understand, but we all know now and then that it was no joke." 
RQ3: What, if any, were the changes in students' perceptions regarding their collaboration between the design and participation phases of learning?

The theme categories that emerged in the design and participation phases were the same: novelty, challenges and strategies, and learning community. However, the ratios of the three categories per phase were significantly different between phases. The reference numbers in open codes for each phase are visualized in a radar chart (see Figure 2) where a higher frequency of a theme category is indicated by a greater distance from the center. Going by proportion, novelty was the most dominant overarching theme compared to the other two themes in the design phase. On the other hand, it was the least dominant overarching theme in the participation phase during which the learning community gained dominance.

Figure 2. The Change in Dominant Themes per Course Phase.

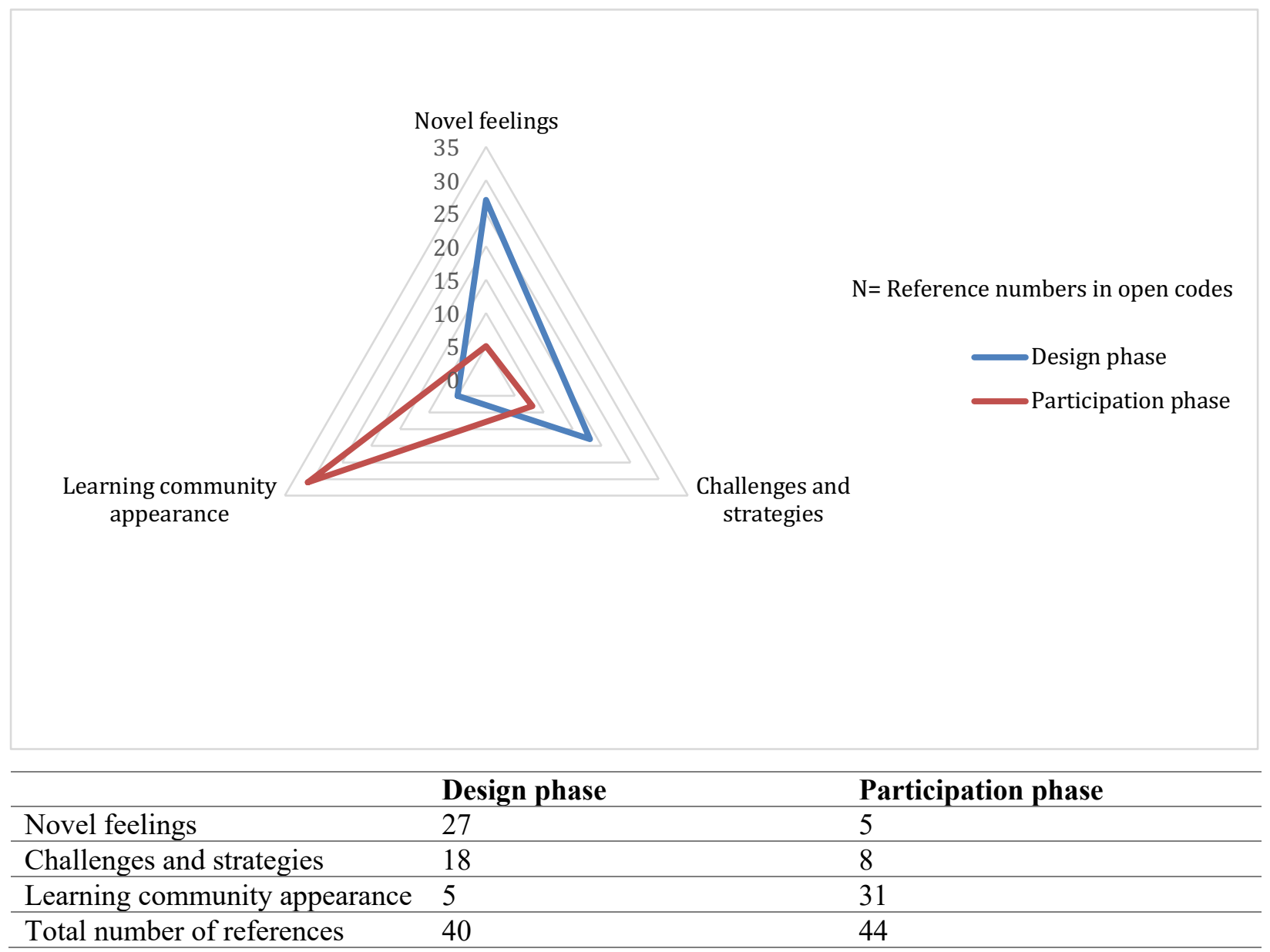

RQ4: What knowledge did students construct per course phase and what overarching themes were identified during the knowledge construction process from the standpoint of the online learning community theory?

Participants constructed knowledge in both design and participation phases from the OCL standpoint as shown in Table 3. Most of the overarching themes that appeared in both phases were 
directly relevant to the knowledge they constructed. For example, "novelty" can be construed as referring to the fun aspect of knowledge in designing and participating in the learning activities in SL. Similarly, "challenges and strategies" led to the creation of knowledge related to overcoming the challenges of using web-based tools and implementing various strategies at different levels in and outside of each team. However, some forms of knowledge creation exhibited a continuous spectrum moving from one overarching theme to another. In particular, the emergence of a classbased learning community originated from identifying and implementing strategies to overcome the challenges participants experienced in both course phases. Nevertheless, the cognizance of the benefits of learning communities expanded among participants when the dominant theme was "learning community" rather than "challenges and strategies." See Table 3 for details related to the knowledge generated in each course phase.

Table 3

Overarching Themes, Examples, and Knowledge Production in the Design and Participation Phases Based on the OCL Theory

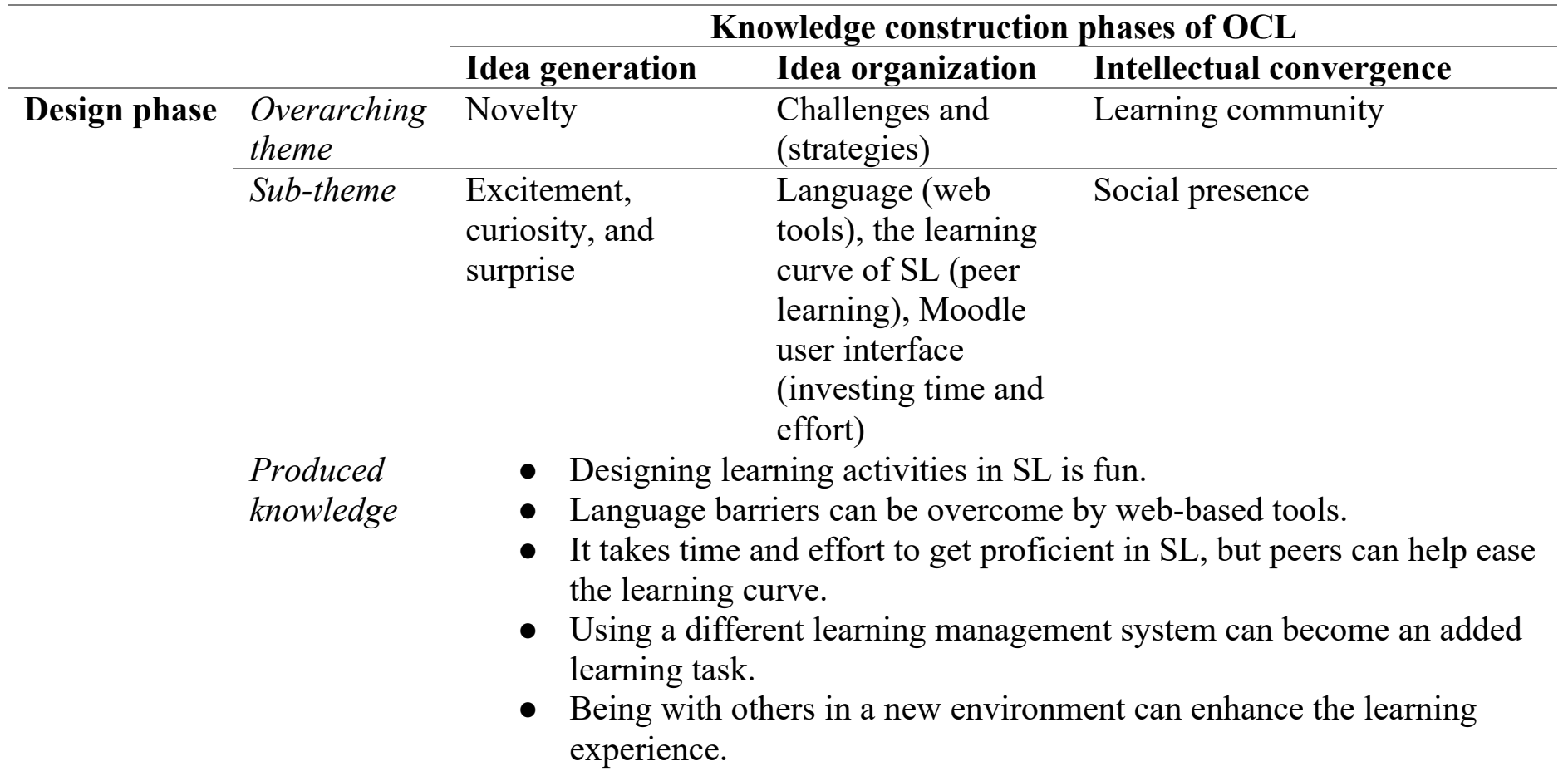


Table 3 (continued)

Overarching Themes, Examples, and Knowledge Production in the Design and Participation Phases Based on the OCL Theory

\begin{tabular}{|c|c|c|c|c|}
\hline & \multicolumn{3}{|c|}{ Knowledge construction phases of OCL } \\
\hline & & Idea generation & Idea organization & Intellectual convergence \\
\hline \multirow[t]{3}{*}{$\begin{array}{l}\text { Participation } \\
\text { phase }\end{array}$} & $\begin{array}{l}\text { Overarching } \\
\text { theme }\end{array}$ & Novelty & $\begin{array}{l}\text { Challenges and } \\
\text { (strategies) }\end{array}$ & Learning community \\
\hline & Sub-theme & $\begin{array}{l}\text { Excitement, } \\
\text { engagement, } \\
\text { curiosity, and } \\
\text { confidence }\end{array}$ & $\begin{array}{l}\text { Limited time } \\
\text { (individual and } \\
\text { team-based } \\
\text { strategies) }\end{array}$ & $\begin{array}{l}\text { Class-based learning } \\
\text { community, constructive } \\
\text { critiques, employment of } \\
\text { multiple competences }\end{array}$ \\
\hline & $\begin{array}{l}\text { Produced } \\
\text { knowledge }\end{array}$ & \multicolumn{3}{|c|}{$\begin{array}{l}\text { - Participating in learning activities in SL is fun. } \\
\text { - Limited time causes challenges in collaboration, but this hurdle can } \\
\text { be overcome through various individual and team-based strategies. } \\
\text { - } \text { learning community depending on the degree of participants' } \\
\text { interaction and its influence on each individual participant's learning. } \\
\text { - Providing constructive critiques for each learning activity designed } \\
\text { by other teams not only helps improve others, but it also could } \\
\text { improve the provider's future work. } \\
\text { - Participants need to apply multiple competencies at the same time } \\
\text { including communication, negotiation, and problem solving to } \\
\text { collaborate successfully while engaging in learning activities } \\
\text { designed by other teams. }\end{array}$} \\
\hline
\end{tabular}

\section{Discussion}

In this section, we examine how participants' construction of new knowledge is a result of authentic learning according to the OCL's three phases of knowledge construction. Additionally, we discuss how this process of knowledge construction enabled participants' authentic learning from a social constructivist perspective.

\section{Knowledge Construction Process and Authentic learning}

From a social constructivist perspective, there are three possible factors that facilitated the participants' authentic learning: (a) taking on multiple roles in class, (b) social presence attributed to collaboration, which in turn resulted in (c) changes in dominant themes in participants' perceptions ranging from the design through participation phases.

\section{Taking on Multiple Roles in Class}

In the design phase, participants mainly took on the roles typically played by teachers in designing learning activities. To ensure that the contextualized learning experiences optimized SL's capabilities, the participants also took on the role of students from time to time, but only to test the quality of the learning activities they designed. In addition, the steep learning curve surrounding familiarization with SL's interface and features further promoted peer teaching and learning. In the participation phase, on the other hand, participants mainly took on student roles. 
They engaged with learning activities designed by other teams while considering ways in which real students would react to those activities, and this consideration produced multi-faceted critiques that came from the teachers' perspective as learning experience designers while playing the role of students (Herrington \& Oliver, 2000). The data we collected in this study indicate that participants experienced the emergence of a class-based learning community that influenced internal change within each participant throughout the duration of the course. As Michael recalled, "a different kind of learning happened." That the implementation of multiple roles broadens students' perspectives across formal and informal learning contexts and facilitates students' authentic learning is a well-established fact not only in virtual world studies but also in wiki and blog adopted educational studies (Titus, 2014). Therefore, we posit that the taking on of multiple roles, in designing and participating in learning activities, may have enabled authentic learning for the participants.

\section{Social Presence}

While the participants described their learning experiences throughout the design and participation phases, some participants particularly emphasized their perceptions related to the social presence in the virtual world. As impressed as the participants were with the "mini-worlds," which they described as "sophisticated and realistic," they seemed to be even more impressed by the manner in which these sophisticated mini-world representations enhanced the connections they felt toward their team members residing in another country. Ali elaborated on this connection with an example: "When we were on the Ferris wheel to capture some geometrical shapes as we [were] instructed to, I was becoming nervous when our ride was going up in the air because I am always afraid of height. Strangely, it was comforting to have my team members on the same ride which was so funny because it was just avatars and it was not even a real ride! But I know I would never go ride that Ferris wheel by myself because I need somebody to be with me no matter whether I am in a real amusement park or SL one." Biocca et al. (2003) report that participants feel psychological involvement such as intimacy and immediacy when the level of social presence is high, as Ali expressed. Bulu (2012) also found that social presence is one of the most important factors in learning processes affecting participants' positive perceptions with respect to learning outcomes. Lee (2004) asserts that "social presence occurs when technology users successfully simulate other humans or nonhuman intelligences" (p. 45), implying that technology can enhance social presence when it is used adequately. Therefore, social presence, enhanced by technologies such as three-dimensional representations and avatar features, may have promoted the participants' authentic learning in this study.

\section{Change of Dominant Themes in the Participants' Perceptions}

In social constructivism, learning occurs at the individual level through collaboration with others, as we observed in both the design and participation phases of this study. This process of learning through collaboration can result in knowledge within contextual learning environments such as SL. We observed the evolution of the students' learning environment from a team-based to a larger class-based learning community, which functioned as a culture wherein all participants shared the same norms in terms of achieving their learning goals. Therefore, the change in the dominant theme, in the participants' perspectives, from mere feelings of novelty at experiencing a virtual world for the first time to developing a robust learning community, may be evidence of the participants' authentic learning. According to Van Oers and Wardekker's (1999) definition of authentic learning, even the students' personality construction was influenced by the cultures 
within their teams as well as the larger class-based team, both of which were in a reconstruction process during this study.

Contrarily, the change can also be conceived as a prerequisite to authentic learning. If students' perceptions had not evolved beyond the superficial sense of novelty, we argue that authentic learning would have been impossible. According to Heath and Mclaughlin (1994) and Hierbert et al. (1996), students must make meaningful connections to their own lived experiences for authentic learning to take place. Novelty, on its own, is merely entertaining and not meaningful. Had the students' perception remained focused on thoughts of excitement toward flying in between realistic 3D buildings in SL for instance, it follows that the students would not have possibly perceived their peers' presence, let alone achieved learning goals through collaboration.

\section{Limitations and Future Research}

While the present study drew several interesting conclusions on the meaning of learners' perception changes during a cross-national collaborative learning course, there are some improvements that can be made in future studies to validate the current findings more robustly. First, not everyone who took the course participated in this study. Even though six out of seven U.S. students volunteered for this study, a much lower rate of Israeli students did so (only 6 out of 15). Further, as this study recruited participants on a voluntary basis, it is possible that only students who had a positive experience in the course volunteered. Hence, future studies would benefit from recruiting more participants, especially from Israel, to verify the current study's findings. Second, the period of collaboration, involving designing and participating in learning activities together with cross-national team members in SL, was limited to a five to six weeks period in this study. In this short period of time, the authors identified major changes in students' perspectives on collaborative learning based on participant responses. The authors further observed the transformation of each team-based learning community as well as their merger into the larger class-based learning community. However, it was a too short period of time to identify the next level of students' perspective changes or the emergence of an even larger learning community than a class-based one, presuming it was possible. Additionally, we had insufficient time to delve into the intercultural literacy component of these students' learning process. Given a longer period of student participation in collaborative learning activities, future researchers may be able to detect the next phase of this collaborative learning experience in terms of intercultural literacy in a virtual world.

\section{Conclusion}

This study revealed that graduate students' perspectives on learning changed significantly per learning phase of a cross-national collaborative learning course set in a virtual world. In the design phase, participants reported being mostly driven by the novelty of engaging in a threedimensional virtual learning environment for the first time. This excitement soon gave way to an increased focus on components related to the "learning community" theme. They then experienced the evolution of a team-oriented learning community before eventually experiencing a class-based evolution as time went on. Participants stated, they experienced intellectual convergence throughout the two phases, which were distinct from their past learning experiences. Based on the confluence of participants' statements with the definitions provided by previous researchers (Heath \& Mclaughlin, 1994; Hierbert et al., 1996; Van Oers \& Wardekker, 1999), the authors deemed this experience as "authentic learning." Thus, the main contribution of this study is the identification 
of the collaborative learning phases, the different themes in students' perspectives per course phase, and the aspects of this learning experience which deem it an authentic learning experience for students within a virtual collaborative learning environment. More importantly, this study's findings are applicable to any virtual world, because latecomers to the virtual world market, such as Minecraft and OpenSim, provide similar user experiences as SL. Their additional functions compared to SL, do not change the fundamental methods of social interaction among the learning community, which is the most crucial aspect of collaborative learning in any learning environment. Regardless of what virtual world is adopted in education, the three possible factors that facilitated the participants' authentic learning in this study - (a) taking on multiple roles in class, (b) social presence attributed to collaboration, and (c) changes in dominant themes in participants' perceptions ranging from the design through participation phases - might help educators and researchers understand on collaborative authentic learning and how to use virtual world effectively in online education.

Although virtual worlds have been adopted in educational contexts for approximately 30 years, many gaps remain in our understanding including how best to use the changes in students' perspectives during the learning process to make their learning experience more authentic when incorporating a virtual world in education. Detecting some of the benefits of adopting virtual worlds in education is only the first step. This field is bound to become more prevalent in the future due to the increasing interest in and necessity for online learning resulting from the pandemic crisis in 2020 as well as the rise in immersive technologies such as VR embodiment. Thus, further research is required to realize the full potential of virtual worlds in education. 


\section{References}

Baker, S. C., Wentz, R. K., \& Woods, M. M. (2009). Using virtual worlds in education: Second Life ${ }^{\circledR}$ as an educational tool. Teaching of Psychology, 36(1), 59-64. https://doi.org/10.1080/00986280802529079

Boniello, A., Paris, E., \& Santoianni, F. (2019). Virtual worlds in geoscience education: Learning strategies and learning 3D environments. In Information Resources Management Association (Ed.), Virtual Reality in Education: Breakthroughs in Research and Practice (pp. 781-800). IGI Global. https://doi.org/10.4018/978-1-5225-81796.ch037

Boulos, M. N. K., Hetherington, L., \& Wheeler, S. (2007). Second Life: An overview of the potential of 3-D virtual worlds in medical and health education. Health Information \& Libraries Journal, 24(4), 233-245. https://pubmed.ncbi.nlm.nih.gov/18005298/

Broadribb, S., \& Carter, C. (2009). Using second life in human resource development. British Journal of Educational Technology, 40(3), 547-550. https://doi.org/10.1111/j.1467$\underline{8535.2009 .00950 . \mathrm{X}}$

Bronack, S., Sanders, R., Cheney, A., Riedl, R., Taschner, J., \& Matzen, N. (2008). Presence pedagogy: Teaching and learning in a 3D virtual immersive world. International Journal of Teaching and Learning in Higher Education, 20(1), 59-69. https://files.eric.ed.gov/fulltext/EJ895226.pdf

Brown, J., Collins, A., \& Duguid, P. (1989). Situated cognition and the culture of learning. Educational Researcher, 18(1), 32-42. www.jstor.org/stable/1176008

Burbules, N. C. (2002). Like a version: Playing with online identities. Educational Philosophy and Theory, 34(4), 387-393. https://doi.org/10.1080/0013185022000011781

Chanprasitchai, O. A., \& Khlaisang, J. (2016). Inquiry-based learning for a virtual learning community to enhance problem-solving ability of applied Thai traditional medicine students. Turkish Online Journal of Educational Technology-TOJET, 15(4), 77-87. http://www.tojet.net/articles/v15i4/1549.pdf

Collins, A. (1988). Cognitive apprenticeship and instructional technology (Technical Report 6899). BBN Labs Inc.

Collins, A., Brown, J. S., \& Newman, S. E. (1989). Cognitive apprenticeship: Teaching the crafts of reading, writing, and mathematics. In L. B. Resnick (Ed.), Knowing, learning and instruction: Essays in honour of Robert Glaser (pp. 453-494). LEA.

De Lucia, A., Francese, R., Passero, I., \& Tortora, G. (2009). Development and evaluation of a virtual campus on Second Life: The case of Second DMI. Computers and Education, 52, 220-233. https://doi.org/10.1016/j.compedu.2008.08.001

Denzin, N. K., \& Lincoln, Y. S. (2008). Introduction: The discipline and practice of qualitative research. In N. K. Denzin \& Y. S. Lincoln (Eds.), Strategies of qualitative inquiry (p. 143). Sage Publications, Inc. 
Dickey, M. D. (2005). Three-dimensional virtual worlds and distance learning: Two case studies of Active Worlds as a medium for distance education. British Journal of Educational Technology, 36(3), 439-451. https://berajournals.onlinelibrary.wiley.com/doi/abs/10.1111/j.1467-8535.2005.00477.x

Dillenbourg, P., Järvelä, S., \& Fischer, F. (2009). The evolution of research on computer supported collaborative learning: From design to orchestration. In: Balacheff N, Ludvigsen S, de Jong T, et al. (Eds.) Technology Enhanced Learning: Principles and Products. New York: Springer, pp. 3-19.

Gee, J. P. (2004). What video games have to teach us about learning and literacy. Computers in Education, 1(1), 20. https://doi.org/10.1145/950566.950595

Greenwald, S., Kulik, A., Kunert, A., Beck, S., Frohlich, B., Cobb, S., ...Newbutt, N. (Eds.). (2017). Technology and applications for collaborative learning in virtual reality [Conference presentation]. 12th International Conference on Computer Supported Collaborative Learning. https://repository.isls.org//handle/1/210

Heath, S. B., \& McLaughlin, M. W. (1994). Learning for anything everyday, Journal of Curriculum Studies, 25(5), 471-489. https://doi.org/10.1080/0022027940260501

Herrington, J., \& Oliver, R. (2000). An instructional design framework for authentic learning environments. Educational Technology Research and Development, 48(3), 23-48. https://ro.uow.edu.au/cgi/viewcontent.cgi?referer=https://www.google.com/\&httpsredir= 1 \&article $=1031 \&$ context=edupapers

Heyward, M. (2002). From international to intercultural: Redefining the international school for a globalized world. Journal of Research in International Education, 1(1), 9-32. https://doi.org/10.1177/147524090211002

Hiebert, J., Carpenter, T. P., Fennema, E., Fuson, K., Human, P., Murray, H., Oliver, A., \& Wearne, D. (1996). Problem solving as a basis for reform in curriculum and instruction: The case of mathematics, Educational Researchers, 25(4), 12-21. www.jstor.org/stable/1176776

Honebein, P. C., Duffy, T. M., \& Fishman, B. J. (1993). Constructivism and the design of learning environments: Context and authentic activities for learning. In T. M. Duffy, J. Lowyck, \& D. H. Jonassen (Eds.), Designing environments for constructive learning (pp. 87-108). Springer-Verlag.

John-Steiner, V., \& Mahn, H. (1996). Sociocultural approaches to learning and development: A Vygotskian framework. Educational Psychologist, 31(3-4), 191-206. https://doi.org/10.1207/s15326985ep3103\&4 4

Kostarikas, I., Varlamis, I., \& Giannakoulopoulos, A. (2016). Blending distance learning

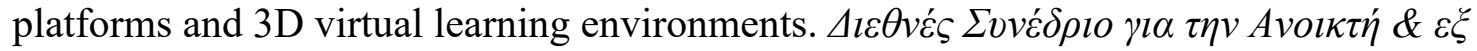

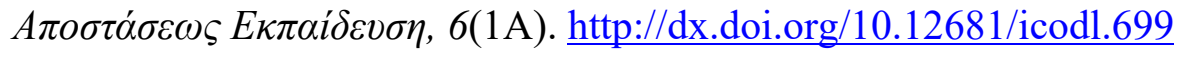

Lave, J., \& Wenger, E. (1991). Situated learning: Legitimate peripheral participation. Cambridge University Press. 
Lee, K. M. (2004). Presence, explicated. Communication Theory, 14(1), 27-50. https://doi.org/10.1111/j.1468-2885.2004.tb00302.x

Lee, M. J. W. (2009). How can 3D virtual worlds be used to support collaborative learning? An analysis of cases from the literature. Journal of e-Learning and Knowledge Society, 5(1), 149-158. https://www.learntechlib.org/p/43518/

Mercer, N. (1996). The quality of talk in children's collaborative activity in the classroom. Learning and Instruction, 6(4), 359-377. https://doi.org/10.1016/S0959-4752(96)00021$\underline{7}$

Mercer, N., \& Howe, C. (2012). Explaining the dialogic processes of teaching and learning: The value and potential of sociocultural theory. Learning, Culture, and Social Interaction, 1(1), 12-21. https://doi.org/10.1016/j.lcsi.2012.03.001

Monahan, C., Ullberg, L., \& Harvey, K. (2009, July). Virtual emergency preparedness planning using second life. In 2009 IEEE/INFORMS International Conference on Service Operations, Logistics and Informatics (pp. 306-310). IEEE. https://doi.org/10.1109/SOLI.2009.5203950

Murray, J. A., Littleton, F., \& Dozier, M. (2015). Use and perception of Second Life by distance learners: The effects of orientation session timing. International Journal of E-learning and Distance Education, 30(1). http://www.ijede.ca/index.php/jde/article/view/898/1575

Ramírez, J., Rico, M., Riofrío-Luzcando, D., Berrocal-Lobo, M., \& de Antonio, A. (2018). Students' Evaluation of a Virtual World for Procedural Training in a Tertiary-Education Course. Journal of Educational Computing Research, 56(1), 23-47. https://doi.org/10.1177/0735633117706047

Reinsmith-Jones, K., Kibbe, S., Crayton, T., \& Campbell, E. (2015). Use of Second Life in social work education: Virtual world experiences and their effect on students. Journal of Social Work Education, 51(1), 90-108. https://doi.org/10.1080/10437797.2015.977167

Resta, P., \& Shonfeld, M. (2014, March). Challenges and strategies in designing trans-national learning team projects in virtual worlds. In Society for Information Technology \& Teacher Education International Conference (pp. 403-409). Association for the Advancement of Computing in Education. https://www.learntechlib.org/primary/p/147335/

Scardamalia, M., Bereiter, K., \& Lamon, M. (1994). The CSILE project: Trying to bring the classroom into world 3. In K. McGilly (Ed.), Classroom lessons: Integrating cognitive theory and classroom practice (pp. 201-228). Bradford Books, MIT Press.

Stake, R. E. (1995). The art of case study research. Sage Publications, Inc.

Stott, D. (2007). Learning the second way. British Medical Journal, 335, 1122-1123. https://doi.org/10.1136/bmj.39400.460139.941

Strauss, A., \& Corbin, J. M. (1990). Basics of qualitative research: Grounded theory procedures and techniques. Sage Publications, Inc. 
Titus, S. (2014). Using wikis and blog to mediate authentic learning: a case of teaching sport science education. Routledge.

Turkle, S. (1995). Life on the screen: identity in the age of the internet. Simon \& Schuster.

Van Oers, B., \& Wardekker, W. (1999). On becoming an authentic learner: Semiotic activity in the early grades, Journal of Curriculum Studies, 31(2), 229-249. https://doi.org/10.1080/002202799183241

von Wright, J. (1992). Reflections on reflection. Learning and Instruction, 2(1), 59-68. https://doi.org/10.1016/0959-4752(92)90005-7

Vuopala, E., Hyvönen, P., \& Järvelä, S. (2016). Interaction forms in successful collaborative learning in virtual learning environments. Active Learning in Higher Education, 17(1), 25-38. https://doi.org/10.1177/1469787415616730

Vygotsky, L. S. (1978). Mind in society. Harvard University Press.

Warburton, S., \& Perez-Garcia, M. (2009). 3D design and collaboration in massively multi-user virtual environments (MUVEs). In D. Russel (Ed.), Cases on collaboration in Virtual Learning Environments: Processes and interactions (pp. 27-41). IGI Global. https://doi.org/10.4018/978-1-60566-878-9.ch002

Wenger, E. (1998). Communities of Practice: Learning, meaning and identity. Cambridge University Press. https://doi.org/10.1017/cbo9780511803932.018

Yin, R. K. (2009). Case study research: Design and methods (4th ed.). Sage Publications, Inc.

Young, M. F. (1993). Instructional design for situated learning. Educational Technology Research and Development, 41(1), 43-58. https://doi.org/10.1007/BF02297091 


\section{Appendix 1}

\section{Semi-structured Interview Questions}

I. Background

- Age Range (18-24/ 25-34/ 35-44/ 45-54/ 55-64)

- Mother tongue?

- How would you describe your English proficiency? Tell me which case describes your overall interaction in the course.

1. I had no problem in understanding any conversations.

2. I could understand most of the conversations but sometimes needed help from other team members to understand what was going on in my team.

3. I barely understood any conversations so that I needed other team members' help in understanding and expressing my opinions most of the time.

- Have you ever explored Second Life before taking the Computer-Supported Collaborative Learning/ Online Environments for Teaching and Learning course? (If the answer is yes) What were the major activities you did in Second Life back then? Do you engage with any other virtual reality application, such as a VR game?

II. Authentic Learning and Second Life

Learning Activity Design

- What was your experience like in designing collaborative learning activities with your team members?

- What were the challenges and successes you encountered in the learning activity development with your team members?

- What strategies did you/your team used to overcome the challenges you described in the learning activity development?

Learning Activity Participation- Amazing Race

- What was your experience like in completing the learning activities designed by other teams?

- What were the challenges and successes you encountered in participating in "Amazing Race" designed by other teams?

- What strategies did you/your team use to complete the learning activities designed by other teams in the Amazing Race?

III. Other Factors in Authentic Learning and Second Life

- Other than the tutorial provided by Second Life (Orientation Island), did you seek other information to learn how to use SL at the beginning of the course? Where/how did you find that information you sought?

- Based on your experience, are you willing to adopt any team activities in a virtual world for your class as a teacher?

- What changes did you experience after developing collaborative learning activities in SL and participating in activities designed by other teams?

- Was it fun to develop learning activities with your team members? If it was engaging for you, can you tell me why you felt that way? 